Original article

\title{
Lower back pain at workplace: prevalence and risk factors
}

\author{
Irina M. Goncharenko ${ }^{1}$, Nataliya E. Komleva ${ }^{1}$, Andrey A. Chekhonatsky ${ }^{2}$
}

${ }^{1}$ Saratov Hygiene Medical Research Center of Federal Scientific Center for Medical and Preventive Health Risk Management Technologies, Saratov, Russia

${ }^{2}$ Saratov State Medical University, Saratov, Russia

Received 19 September 2019, Revised 9 January 2020, Accepted 14 April 2020

(C) 2019, Goncharenko I.M., Komleva N.E., Chekhonatsky A.A.

(C) 2019, Russian Open Medical Journal

Abstract: Objective - analysis of lower back pain (LBP) prevalence and risk factors for its development in employees with different conditions at their workplace, depending on their age, length of service, occupational factors, and physical activity.

Material and Methods - As a result of a simultaneous cross-sectional study, 3300 employees with different conditions at their workplace were examined. To study the relationships between LBP prevalence and risk factors, we used the results of employees' survey and physical examination, along with the data on their physical activity and working conditions.

Results - The workplace posture was the most common production-related risk factor for developing LBP. The second most common risk factor was the weight of the load being lifted and carried, followed by general vibration at a workplace. The least significant factor was a bending motion. According to our data, LBP prevalence in all observation groups was increasing with both age and length of employment. Over $50 \%$ of those working in hazardous conditions at the age of 50 yo and higher had LBP. Low physical activity at a workplace led to a statistically significant increase in the chances of LBP emergence.

Conclusion - In employees without exposure to harmful risk factors in the form of physical exertion and general vibration, the prevalence of LBP was significantly lower than in workers in harmful working conditions. The combined effect of static and dynamic physical activities at a workplace had a more pronounced negative impact on workers' health. Low physical activity was a significant risk factor for LBP development.

Keywords: lower back pain, workplace factors, physical activity.

Cite as Goncharenko IM, Komleva NE, Chekhonatsky AA. Lower back pain at workplace: prevalence and risk factors. Russian Open Medical Journal 2020; 9 : e0207.

Correspondence to Irina M. Goncharenko. E-mail: irgomas@mail.ru. Address: Saratov Hygiene Medical Research Center, 1A, Zarechnaya str., Saratov, 410022, Russia.

\section{Introduction}

Lower back pain (LBP) is among the most frequent complaints of patients visiting general practitioners $[1,2]$. It is a healthcare problem on the global scale [3, 4], affecting over $80 \%$ of adult population $[1,3]$. LBP syndrome involves painful sensations localized between the rib pair 12 and gluteal sulcus, including pain in crus and thigh, while excluding pain caused by pregnancy, menstruation, viral infection or cancer $[3,5]$.

The main risk factors for LBP are classified as individual, psychosocial, and occupational. Individual factors include obesity, age [5], smoking, low educational level [2], high pain levels and disability [2, 6]. Psychosocial causes involve stress [7], layoff anxiety, depressive disorders, negative emotions [8], low healthcare quality, and unemployment [9]. Significant productionrelated risk factors are turns and bending motions of a worker's torso, lifting and carrying weights $[10,11]$, static workplace posture $[11,12]$, vibration at a workplace [13], low work qualification, monotony of performed work, and uniformity of work operations [14]. It is typical that too low, or too intense, physical activity at a workplace [10], as well as heavy physical activities unrelated to a job [9], contribute to emergence of pathological vertebrogenic processes and affect developing occupational pathology $[11,15]$.

Study objective: analysis of LBP prevalence and risk factors for its development in employees with different conditions at their workplace, depending on their age, length of service, productionrelated factors, and physical activity.

\section{Material and Methods}

\section{Study design}

It is simultaneous cross-sectional study in the course of periodic medical examinations with direct participation of the authors.

Inclusion criteria:

i) Male and female employees,

ii) At the age of 20-60 yo,

iii) Signatories of informed consent to participate in the study. 
Exclusion criteria:

i) Pregnancy and breastfeeding,

ii) Infectious and oncological diseases,

iii) History of lumbosacral spine injury,

iv) Comorbid pathology in the stage of exacerbation or decompensation.

The study encompassed 3,300 employees of industrial and agricultural enterprises, and the Volga Branch of Russian Railways OJSC over the period of 2016-2019. Of these, 2485 (76.8\%) were men, and 815 (23.2\%) were women. We developed a formalized medical record6 in which the data for each study participant were recorded:

i) Gender,

ii) Age,

iii) Duration of employment,

iv) Employee complaints,

v) Vertebral neurological examination data,

vi) Presence of concomitant pathology (joint disorders, dorsopathy of cervical spine, diseases of cardiovascular and digestive systems),

vii) Indicator of physical activity,

viii) Typical workplace conditions (professional risk factors for LBP).

To assess levels of physical exertion, we used International Physical Activity Questionnaire (IPAQ) [15, 16], based on taking into account five physical activity domains within 24 hours: jobrelated physical activity [17]; transportation (walking, cycling, riding a bus/train, or driving); housework, house maintenance, and gardening; sports and recreation; time spent sitting [18]. Information obtained from a questionnaire of a worker while undergoing a periodic medical examination was also entered into a formalized medical record and a database, and then processed strictly in accordance with the algorithm recommended by IPAQ developers. Physical activity was measured in $\mathrm{kcal} / \mathrm{min}$ or metabolic equivalents of task (MET) as a reference - that is, in energy costs for certain activities. $1 \operatorname{MET}[15,16]$ is the rate of energy use in a state of complete rest, which is $2.6-6.2 \mathrm{~kJ} / \mathrm{min}(1.1-$ $1.25 \mathrm{kcal} / \mathrm{min}$ ). Conventionally, $1 \mathrm{MET}=3.5 \mathrm{ml} \mathrm{O} / \mathrm{kg} / \mathrm{min}$.

Occupational risk factors for developing back pain were assessed in accordance with the Guidelines R 2.2.2006-05 on the hygienic assessment of workplace environment and labor process factors.

\section{Criteria and classification of working conditions}

1. General vibration (per shift: class $3.1-6 / 2 \mathrm{~dB} /$ time; class 3.2 -12/4 dB/time; class $3.3-18 / 6 \mathrm{~dB} /$ time).

2. Physical dynamic load: the mass of load being lifted and carried manually (class 3.1 - up to $1500 \mathrm{~kg}$ for men, and up to 700 $\mathrm{kg}$ for women; class 3.2 - over $1500 \mathrm{~kg}$ for men, and over $700 \mathrm{~kg}$ for women).

3. Static load: bending motions (class 3.1 - 101-300 per shift; class 3.2 - over 300 per shift); workplace posture (class 3.1 periodic, up to $50 \%$ of the shift time in a fixed position; class $3.2-$ periodic, over $50 \%$ of the shift time in a fixed position).

All study participants were divided into 4 subgroups by age and length of employment. Distribution of the subjects by adverse occupational factor was conducted after analyzing the data from workplace certification cards and protocols for assessing working conditions via indicators of the work process severity.
Group I consisted of 801 people employed in working conditions, characterized by a combination of dynamic and static physical activities (average age 40.1 \pm 1.8 ). Representatives of this group were characterized by working conditions classes 3.2-3.3.

Group II comprised of 827 people working under conditions of physical dynamic activity (average age $40.4 \pm 2.0$ ). The severity of physical labor in these professions qualified as class 3.1 and above.

Group III included 747 people working under conditions of excessive static physical activity (average age $39.6 \pm 1.8$ ). The severity of physical labor corresponded to class 3.1 and higher.

Group IV encompassed 826 employees of auxiliary services and plant management, whose working conditions were not related to exposure to harmful occupational factors (average age $41.2 \pm 1.6)$. The severity of physical labor in these professions qualified as class 2.0

\section{Statistical analysis}

After the database was formed, some continuous variables were discretized for analysis using contingency tables. The intergroup differences in the indicators relative to a particular categorized variable were evaluated both visually, by plotting graphs with corresponding confidence limits for average values, and analytically, by using analysis of variance and Student's statistical criteria (for continuous variables), along with MannWhitney test (for categorized variables). The relationship between categorized variables and LBP was assessed by constructing multilevel contingency tables and forming a reduced $2 \times 2$ contingency table with frequencies corresponding to estimated exposure levels of the factor. In order to obtain correct conclusion about the effect presence or absence, the odds ratios (OR) were calculated, along with their $95 \%$ confidence intervals. The presence of multilevel contingency tables makes it possible to compare the significance of the effect on the prevalence of NES of a particular exposure level of a risk factor relative to any other level.

To assess the combined effect of risk factors in relation to LBP prevalence, the multilevel contingency tables were reduced to a $2 \times 2$ table by selecting the appropriate frequency values that adequately reflected the study goal. Consequently, the ORs were calculated with corresponding $95 \%$ confidence intervals.

\section{Results}

In the formed subgroups, we studied LBP prevalence and OR versus duration of professional affiliation and age (Table 1). OR values were computed relative to the first group by, using age class "20-29 yo". The relationships among harmful occupational factors and LBP prevalence for all study participants were studied without specifying the nature and severity of risk factors' values based on univariate analysis (Table 2). More detailed information was provided by multivariate analysis (Table 3 ).

In group I (working under the combined effects of static and dynamic physical activities), the highest LBP prevalence and ORvalue were noted for the age range of $40-49$ years $(74.2 \%$; OR $=7.86$; $95 \% \mathrm{Cl} 1.83-31.14 ; p=0.038)$. The smallest LBP prevalence was detected in the age range of $20-29$ years $(27.3 \%)$. It should be noted that $71.2 \%-74.2 \%(p<0.05)$ of the surveyed workers of all ages, except 20-29 yo, in this group had LBP syndrome. 
Table 1. LBP prevalence by age and duration of employment (one-way ANOVA)

\begin{tabular}{|c|c|c|c|c|c|c|c|c|}
\hline Groups & 1 & P-level & II & P-level & III & P-level & IV & P-level \\
\hline \multicolumn{9}{|c|}{ Age groups } \\
\hline \multicolumn{9}{|l|}{$20-29$} \\
\hline $30-39$ & 6. $9(1.69-28.86)$ & 0.027 & $1.82(1.01-3.26)$ & 0.031 & $2.10(1.33-3.30)$ & 0.021 & $1.45(0.88-2.42)$ & 0.032 \\
\hline $40-49$ & $7.86(1.83-31.14)$ & 0.038 & $3.59(1.75-5.69)$ & 0.020 & $2.16(1.47-2.77)$ & 0.018 & $2.89(1.77-4.74)$ & 0.024 \\
\hline 50 and over & $6.59(1.56-27.85)$ & 0.033 & $3.40(1.83-6.30)$ & 0.014 & $2.54(1.52-4.25)$ & 0.025 & $2.54(1.52-4.25)$ & 0.029 \\
\hline \multicolumn{9}{|c|}{ Duration of employment groups } \\
\hline \multicolumn{9}{|l|}{$1-9$} \\
\hline $10-14$ & $1.42(1.04-1.82)$ & 0.013 & $1.53(1.09-2.56)$ & 0.022 & $1.09(0.85-1.38)$ & 0.026 & $1.29(0.90-1.86)$ & 0.050 \\
\hline $15-19$ & $1.91(1.46-2.61)$ & 0.027 & $1.61(1.13-2.29)$ & 0.046 & $2.31(1.55-3.43)$ & 0.034 & $1.58(1.11-2.25)$ & 0.028 \\
\hline 20 and over & $2.74(2.14-3.44)$ & 0.019 & $2.19(1.62-2.95)$ & 0.015 & $3.52(2.44-4.98)$ & 0.012 & $6.59(1.56-27.85)$ & 0.001 \\
\hline
\end{tabular}

Table 2. The impact of harmful workplace condition factors on LBP prevalence (one-way ANOVA)

\begin{tabular}{lcc}
\hline Risk factors & Prevalence of dorsopathies, \% & Odds ratio (95\% Cl) \\
\hline General vibration & 64.6 & $2.96(2.316-3.79)$ \\
Weight of a load to be lifted and carried & 56.5 & $2.2(1.81-2.67)$ \\
Torso bending motions & 56.0 & 0.017 \\
Workplace posture (workplace conditions class 3.1-3.2) & $4.89(1.39-2.56)$ \\
\hline
\end{tabular}

Table 3. The impact of workplace condition factors and physical activity on LBP prevalence (two-way and three-way ANOVA)

\begin{tabular}{|c|c|c|c|c|c|c|c|c|}
\hline \multirow{2}{*}{ Risk factors } & Group I & P-level & Group II & P-level & Group III & P-level & Group IV & P-level \\
\hline & \multicolumn{8}{|c|}{ OR $(95 \% \mathrm{Cl})$} \\
\hline General vibration & $1.1(0.69-1.89)$ & 0.031 & $2.6(1.79-3.93)$ & 0.022 & $3.7(2.32-5.9)$ & 0.019 & $1.8(1.23-2.82)$ & 0.041 \\
\hline General vibration and low physical activity in free time & $1.02(0.99-1.04)$ & 0.140 & $2.4(1.58-3.55)$ & 0.034 & $3.6(2.26-5.75)$ & 0.026 & $3.1(1.81-6.04)$ & 0.029 \\
\hline General vibration and sitting posture at workplace & $0.94(0.88-1.05)$ & 0.062 & $2.5(1.64-3.74)$ & 0.028 & $4.04(1.60-10.21)$ & 0.013 & $2.1(1.26-3.59)$ & 0.032 \\
\hline
\end{tabular}

I - people employed in working conditions, characterized by a combination of dynamic and static physical stress; II - people working under conditions of physical dynamic stress; III - people working under conditions of excessive static physical activity; IV - without excessive physical stress at workplace.

In group II (working in conditions of dynamic physical stress), the highest LBP prevalence was observed in the age range of 50 yo and above: $65.1 \%$; OR=3.40; $95 \% \mathrm{Cl} 1.83-6.30 ; p=0.014$. The lowest prevalence was found for the age range of $20-29$ yo (35.5\%).

In group III (working under exposure to excessive static physical activities), the highest LBP prevalence was found in the age range of $40-49$ yo: $55.2 \%$; $\mathrm{OR}=2.16 ; 95 \% \mathrm{Cl} 1.47-2.77 ; p=0.018$. In the age range of 20-29 yo, LBP prevalence was $37.0 \%$.

The lowest LBP prevalence for all age intervals was found in group IV (those, working without physical activity). In this group, the highest was discovered in the age range of $40-49$ yo $37.3 \%$; $\mathrm{OR}=2.89 ; 95 \% \mathrm{Cl} 1.77-4.74 ; p=0.024)$. The lowest LBP prevalence was detected in the age range of $20-29$ yo (17.0\%).

We also analyzed the prevalence and chances of developing LBP, depending on professional affiliation and length of service. OR was calculated relative to the group I, using duration of employment class of 1-9 yr (Table 3).

In group I (working in conditions of combined exposure to static and dynamic physical workload), the highest LBP prevalence was noted for employment duration of $20 \mathrm{yr}$ and over: 68.2\%; $\mathrm{OR}=2.74 ; 95 \% \mathrm{Cl}$ 2.14-3.44; $p=0.019$. The lowest LBP prevalence (26.2\%) was detected for the range of 1-9 yr of employment.

In group II (working in conditions of dynamic physical stress), the highest LBP prevalence and chances of its emergence were also noted, as in group I, for employment duration of $20 \mathrm{yr}$ and over: $68.1 \%$; OR=2.19; $95 \% \mathrm{Cl} 1.62-2.95 ; p=0.015$. The smallest LBP prevalence was found in the range of $1-9 \mathrm{yr}$ of service (31.6\%).
In group III (working under the exposure to excessive static physical activities), the highest LBP prevalence was observed for duration of employment of $20 \mathrm{yr}$ and more: $63.9 \%$; OR=3.52; $95 \%$ $\mathrm{Cl} 2.44-4.98 ; p=0.012$. In the experience range of $1-9 \mathrm{yr}$, LBP prevalence was the lowest (33.6\%).

The lowest LBP prevalence in all lengths of employment intervals was discovered in group IV of those, working without physical exertion. In the ranges of experience of 15-19 yr and $20 \mathrm{yr}$ or more, LBP prevalence was the highest for this group of subjects and amounted to $34.0 \% ; \mathrm{OR}=1.58 ; 95 \% \mathrm{Cl} 1.11-2.25 ; p=0.028$ and 34.1\%; OR=1.89; $95 \% \mathrm{Cl} 1.28-2.79 ; p=0.001$, respectively. The lowest LBP prevalence $(21.5 \%)$ was detected among the workers with experience 1-9 yr.

An analysis of the relationships between harmful occupational factors and LBP prevalence among study participants revealed that its highest values were found among the workers exposed to general vibration exceeding the maximum permissible levels (64.6\%). The bending motion and the weight of the load being lifted and carried augmented LBP prevalence up to $56.0 \%$, while the workplace posture (working conditions classes 3.1-3.2 according to the protocols for assessing the severity of the labor process) increased the chances of LBP development by 1.42 times $(p=0.025)$, and LBP prevalence up to $46.5 \%$.

Using multivariate analysis, we established that, in the group I, the combined effect of dynamic and static physical loads in the presence of general vibration slightly increased the chances of LBP emergence in employees: $\mathrm{OR}=1.1(p=0.031)$.

An effect of general vibration on the group II was the most significant, since appearance of a low physical activity in workers' 
free time or their prolonged stay in a sitting position at a workplace did not lead to expected increase in the chances of developing LBP (OR=2.4; $p=0.034$ and $\mathrm{OR}=2.5 ; \quad p=0.028$, respectively), as occurred in group III, where higher chances of LBP emergence $(\mathrm{OR}=4.04 ; p=0.013)$ were observed in the workers who stayed in a sitting position over $3 \mathrm{hr}$ daily and were exposed to general vibration. However, the study results demonstrated that, in group III, against the background of general vibration $(O R=3.7$; $p=0.019$ ), low physical activity did not have any significant effect on increasing the chances of developing LBP (OR=3.6; $p=0.026)$. We would like specifically emphasize that, in the group of people working without physical exertion (group IV), the combined effect of general vibration at a workplace and low physical activity in workers' free time $(\mathrm{OR}=3.1 ; p=0.029)$, along with general vibration and sitting posture $(\mathrm{OR}=2.1 ; p=0.032)$, exhibited the strongest influence on increase in the chances of LBP emergence.

\section{Discussion}

We have analyzed LBP prevalence and chances of its developing depending on professional affiliation, physical activity, age and duration of employment.

In the observation group I, the highest LBP prevalence was noted for the age range of $40-49$ yo $(74.2 \%$; OR=7.86; $95 \% \mathrm{Cl} 1.83$ 31.14; $p=0.038)$. The lowest LBP prevalence was detected in the age class of $20-29$ years $(27.3 \%)$. It should be noted that in this group of workers, for all age ranges, except for the interval of 2029 yo, from $71.2-74.2 \%(p<0.05)$ of the surveyed had LBP. In the observation group II, the highest LBP prevalence was observed in the age range of 50 yo and older $(65.1 \%$; $O R=3.40 ; 95 \% \mathrm{Cl} 1.83$ $6.30 ; p=0.014)$. The lowest LBP prevalence was characteristic for workers in the age range of $20-29$ yo (35.5\%). In the observation group III, the highest LBP prevalence was detected in the age class of $40-49$ yo $(55.2 \%$; OR=2.16; $95 \% \mathrm{Cl} 1.47-2.77 ; p=0.018$ ). In the age class of $20-29$ yo, LBP prevalence was $37.0 \%$. The lowest LBP prevalence in all age intervals was detected in group IV. In this group, the highest LBP prevalence was also noted in the age range of $40-49$ yo (37.3\%; OR=2.89; $95 \% \mathrm{Cl} 1.77-4.74 ; p=0.024)$. The smallest value of LBP prevalence was discovered in the age range of $20-29$ yo (17.0\%).

When studying LBP prevalence depending on duration of work experience, it was found that, in group I, the frequency of the studied pathology was detected in the experience range of $20 \mathrm{yr}$ or more (68.2\%; OR=2.74; $95 \% \mathrm{Cl} 2.14-3.44 ; p=0.019)$, while the lowest LBP prevalence (26.2\%) was found in the range of 1-9 yr of service. In group II, the highest prevalence and chances of LBP emergence were noted, just as in group $\mathrm{I}$, in the experience class of $20 \mathrm{yr}$ or more $(68.1 \%$; OR=2.19; $95 \% \mathrm{Cl} 1.62-2.95 ; p=0.015)$, whereas the lowest prevalence was found for the range class of 1$9 \mathrm{yr}$ of work experience (31.6\%). In group III, the highest LBP prevalence was observed in the experience range of $20 \mathrm{yr}$ and more (63.9\%; OR=3.52; $95 \% \mathrm{Cl} 2.44-4.98 ; p=0.012)$. In the experience of 1-9 yr, LBP prevalence was the lowest (33.6\%). The smallest LBP prevalence value in all the service intervals was detected in the observation group IV. In the experience ranges of $15-19 \mathrm{yr}$ and $20 \mathrm{yr}$ or more, LBP prevalence was the highest for this group of subjects and amounted to $34.0 \%$; OR=1.58; $95 \% \mathrm{Cl} 1.11$ 2.25; $p=0.028$ and 34.1\%; OR=1.89; $95 \% \mathrm{Cl} 1.28-2.79 ; p=0.001$, respectively. The smallest LBP prevalence value $(21.5 \%)$ was found among the workers with experience from 1-9 yr.
LBP prevalence in all observation groups, which we formed based on workplace conditions, increased with age and duration of employment. In our opinion, this was due to the presence of occupational risk factors, as well as physiological degenerative and dystrophic changes in the spine, joints and surrounding tissues, forming over the course of a person's life, in their turn, with age and exposure to occupational risks. These results are consistent with four-year studies in Spain [19], Nigeria [20], Latin America [21], and Europe [5, 22].

An analysis of the relationship between harmful occupational factors and LBP prevalence among the study participants revealed that the highest prevalence was typical for workers who were exposed to general vibration exceeding the maximum permissible levels (64.6\%). LBP prevalence in workers increased up to $56.0 \%$ with bending motions and weight of the load being lifted and carried. Workplace posture (class of working conditions 3.1-3.2, according to the protocols for assessing the severity of the labor process) increased chances of LBP development by 1.42 times, and its prevalence up to $46.5 \%$.

The leading role among occupational risk factors is played by performing work with significant static and dynamic exertion of the muscles in human trunk, legs and arms; with frequent deep bending motions of the body, twisting of the trunk [10, 11], prolonged stay in a fixed sitting position and leaning over the desk $[11,12]$, and exposure to general vibration at a workplace [13], exceeding the maximum permissible levels.

Using multivariate analysis, we revealed that, in the $1^{\text {st }}$ observation group, the combined effect of dynamic and static physical loads in the presence of general vibration slightly increased the chances of LBP emergence in workers (OR=1.1; $p=0.031$ ). Influence of general vibration on group II subjects was most significant, since low physical activity in their free time or prolonged sitting did not lead to expected increase in the chances of developing LBP (OR=2.4; $p=0.034$ and $O R=2.5 ; p=0.028$, respectively), as occurred in group III, where higher chances of LBP emergence $(O R=4.04)$ were observed in workers spending over three hours a day in a sitting position and exposed to general vibration. However, the results of our study showed that, in group III, against the background of general vibration (OR=3.7; $p=0.019)$, low physical activity did not have any significant effect on increasing chances to developy LBP (OR=3.6; $p=0.026)$. Very interesting finding from our study implied that, in the group of people working without physical exertion (group IV), the cumulative effect of general vibration at a workplace and low physical activity in their free time $(O R=3.1 ; p=0.029)$, along with general vibration and a sitting posture $(\mathrm{OR}=2.1 ; p=0.032)$, had the strongest effect on LBP emergence.

Our data indicate that combined effect of static physical activity with staying at a workplace in a fixed sitting position over three hours, rather than static physical activity alone, leads to increasing LBP. These results complement the studies of E.F. Chernikova [23], S. Bao [24], A. Bazazan [25], and F. Omokhodion [20]. The data from our study confirm the conclusions of foreign scientists that, staying in a sitting position, a forced workplace posture, or lifting and moving heavy cargo, considered as independent risk factors, do not affect the likelihood of developing LBP. To date, there is no reliable evidence of a relationship between occupational pathology of the lumbar spine and the isolated effects of aforementioned occupational risk factors [26, 27]. 
Currently, no sufficient attention is paid to assessing the levels of physical development in workers. In our opinion, it is advisable to focus on workers' physical development and physical difficulty of their performed work responsibilities, since underdeveloped skeletal muscle, under the influence of adverse occupational factors, will predispose to earlier development of pathological processes in the spinal-motor segment, which, in turn, will inevitably lead to LBP emergence.

It is well-known that low levels of physical activity, or too intense physical activity at a workplace, as well as physical activity in workers' free time, contribute to the development of professional-grade LBP [28]. The outcomes of the studies conducted in Latin America [21] and Europe [17, 29] confirmed our results on the effect of physical development and a sedentary lifestyle on increasing LBP prevalence among workers.

\section{Conclusion}

We discovered that, for workers without exposure to harmful risk factors in the form of physical exertion, LBP prevalence was significantly lower than for workers exposed to harmful working conditions. Moreover, over $50 \%$ of those with occupational hazards, aged 50 yo and older, have manifestations of LBP. The results of our study imply that the combined effect of static and dynamic physical exertion of the labor process has a greater negative impact on workers' health, compared with those, working solely under static (or only under dynamic) physical activity conditions (LBP prevalence exceeded 70\%).

Currently, insufficient attention is paid to such important risk factor for developing LBP, as low physical activity at the workplace and in free time. This becomes especially relevant when solving expert issues about the relationship between LBP and profession. However, at present, conducting such studies is difficult due to the lack of physiological and hygienic criteria regulating the levels of physical activity, both at workplace and in everyday life.

\section{Conflict of interest}

None declared.

\section{Ethical approval}

The study was approved by the Ethics Committee at the Saratov Hygiene Medical Research Center of the Federal Budget Scientific Institution "Federal Scientific Center for Medical and Preventive Health Risk Management Technologies". All study participants gave voluntarily consent in accordance with the requirements of bioethics and the Declaration of Helsinki.

\section{References}

1. Schaafsma F, Schonstein E, Ojajдrvi A, Verbeek J. Physical conditioning programs for improving work outcomes among workers with back pain. Scand J Work Environ Health 2011; 37(1): 1-5. https://doi.org/10.5271/sjweh.3078.

2. Steffens D, Maher CG, Pereira LS, Stevens ML, Oliveira VC, Chapple M, et al. Prevention of low Back pain: a systematic review and metaanalysis. JAMA Intern Med 2016; 176(2): 199-208. https://doi.org/10.1001/jamainternmed.2015.7431.

3. Pizova NV. Some of the pain features at the bottom of the back. Medical Council 2017; (10): 110-117. Russian. https://doi.org/10.21518/2079-701X-2017-10-110-117.

4. Driscoll T, Jacklyn G, Orchard J, Passmore E, Vos T, Freedman G, et al. The global burden of occupationally related low back pain: estimates from the Global Burden of Disease 2010 study. Ann Rheum Dis 2014; 73(6): 975-981. https://doi.org/10.1136/annrheumdis-2013-204631.

5. Noormohammadpour P, Mansournia MA, Asadi-Lari M, Nourian R, Rostami M, Kordi R. A subtle threat to urban populations in developing countries: low back pain and its related risk factors. Spine (Phila Pa 1976) 2016, 41(7):
618-627. http://doi.org//10.1097/BRS.0000000000001269.

6. Rolli Salathé C, Melloh M, Mannion AF, Tamcan Ö, Müller U, Boos N, et al. Resources for preventing sickness absence due to low back pain. Occup Med (Lond) 2012; 62(4): 273-280. https://doi.org/10.1007/s10926-006-9061-0.

7. Sterud T, Tynes T. Work-related psychosocial and mechanical risk factors for low back pain: a 3-year follow-up study of the general working population in Norway. Occup Environ Med 2013; 70(5): 296 302. https://doi.org/10.1136/oemed-2012-101116.

8. Halonen JI, Shiri R, Magnusson Hanson LL, Lallukka T. Risk and Prognostic Factors of Low Back Pain. (Phila Pa 1976) 2019; 44(17): 1248-1255. https://doi.org/10.1097/brs.0000000000003052.

9. Farioli A, Mattioli S, Quaglieri A, Curti S, Violante FS, Coggon D. Musculoskeletal pain in Europe: the role of personal, occupational and social risk factors. Scand J Work Environ Health 2014; 40(1): 36-46. https://doi.org/10.5271/sjweh.3381.

10. Bonde JP, Jorgensen KT, Bonzini $M$, Palmer KT. Miscarriage and occupational activity: a systematic review and meta-analysis regarding shift work, working hours, lifting, standing and physical workload. Scand J Work Environ Health 2013; 39(4): 325-334. https://doi.org/10.5271/sjweh.3337.

11. Holtermann A, Clausen T, Aust B, Mortensen OS, Andersen LL. Risk for low back pain from different frequencies, load mass and trunk postures of lifting and carrying among female healthcare workers. Int Arch Occup Environ Health 2013; 86(4): 463-470. https://doi.org/10.1007/s00420-012-0781-5.

12. Bao S, Howard N, Spielholz P, Silverstein B, Polissar N. Comparison of two different methods for performing combination analysis of force and posture risk factors in an epidemiological study. Scand J Work Environ Health 2011; 37(6): 512-524. https://doi.org/10.5271/sjweh.3166.

13. Miedema HS, van der Molen HF, Kuijer PP, Koes BW, Burdorf A Incidence of low back pain related occupational diseases in the Netherlands. Eur J Pain 2014; 18(6): 873-882. https://doi.org/10.1002/j.1532-2149.2013.00430.x.

14. Ye $S$, Jing $Q$, Wei $C$, Lu J. Risk factors of non-specific neck pain and low back pain in computer-using office workers in China: a crosssectional study. BMJ Open 2017; 7(4): e014914 https://doi.org/10.1136/bmjopen-2016-014914.

15. Amlaev KR, Koychueva SM, Koychuev AA, Horoshilova EYu. Hypodynamia: how to break the situation. The modern recommendations about planning the physical activity(review). Izvestia of RAS SamSC 2012; 14(5-2): 518-522. Russian https://elibrary.ru/item.asp?id=19009672.

16. Bubnova MG, Aronov DM, Boytsov SA. Provisioning of physical activity to the residents with health restrictions. Guidelines. Moscow: State Research Center for Preventive Medicine. 2015: 95 p. Russian. https://elibrary.ru/item.asp?id=25839832.

17. Wallmann-Sperlich B, Froboese I. Physical activity during work, transport and leisure in Germany - prevalence and socio-demographic correlates. PloS One 2014; 9(11): e112333. https://doi.org/10.1371/journal.pone.0112333.

18. Holtermann A, Clausen T, Jørgensen MB, Mork PJ, Andersen LL. Should physical activity recommendation depend on state of low back pain? Eur J Pain 2014; 18(4): 575-581. https://doi.org/10.1002/j.15322149.2013.00403.x.

19. Palacios-Ceña D, Alonso-Blanco C, Hernández-Barrera V, CarrascoGarrido $P$, Jiménez-García R, Fernández-de-las-Peñas $C$. Prevalence of neck and low back pain in community-dwelling adults in Spain: an updated population-based national study (2009/10-2011/12). Eur Spine J 2015; 24(3): 482-492. https://doi.org/10.1007/s00586-0143567-5. 
20. Omokhodion FO, Sanya AO. Risk factors for low back pain among office workers in Ibadan, Southwest Nigeria. Occup Med (Lond) 2003; 53(4): 287-289. https://doi.org/10.1093/occmed/kqg063.

21. Garcia JB, Hernandez-Castro JJ, Nunez RG, Pazos MA, Aguirre JO, Jreige $A$, et al. Prevalence of low back pain in Latin America: a systematic literature review. Pain Physician 2014; 17(5): 379-391. https://pubmed.ncbi.nlm.nih.gov/25247896.

22. Plouvier S, Gourmelen J, Chastang JF, Lanoë JL, Leclerc A. Low back pain around retirement age and physical occupational exposure during working life. BMC Public Health 2011; 11: 268. https://doi.org/10.1186/1471-2458-11-268.

23. Chernikova EF, Troshin VV, Nekrasova MM, Zuev AV. Professional conditioning of the formation of diseases of the musculoskeletal system in traffic police inspectors. Russian Journal of Occupational Health and Industrial Ecology 2019; 1(10): 899-904. Russian. https://doi.org/10.31089/1026-9428-2019-59-10-899-904.

24. Bao S, Howard N, Spielholz P, Silverstein B, Polissar N. Comparison of two different methods for performing combination analysis of force and posture risk factors in an epidemiological study. Scand J Work Environ Health 2011; 37(6): 512-524. https://doi.org/10.5271/sjweh.3166.

25. Bazazan A, Dianat I, Feizollahi N, Mombeini Z, Shirazi AM, Castellucci HI. Effect of a posture correction-based intervention on musculoskeletal symptoms and fatigue among control room operators. Appl Ergon 2019; 12-19. https://doi.org/10.1016/j.apergo.2018.11.008.

26. Roffey DM, Wai EK, Bishop P, Kwon BK, Dagenais S. Causal assessment of awkward occupational postures and low back pain: results of a systematic review Spine J 2010; 10(1): 89-99. https://doi.org/10.1016/i.spinee.2009.09.003.

27. Wai EK, Roffey DM, Bishop P, Kwon BK, Dagenais S. Causal assessment of occupational lifting and low back pain: results of a systematic review. Spine J 2010; 10(6): 554-566 https://doi.org/10.1016/j.spinee.2010.03.033.

28. Chang Q, Wei F, Zhang L, Ju X, Zhu L, Huang C, et al. Effects of Vibration in Forced Posture on Biochemical Bone Metabolism Indices, and Morphometric and Mechanical Properties of the Lumbar Vertebra. $\begin{array}{llll}\text { PLOS ONE } & \text { 2013; } & \text { e78640 }\end{array}$ https://doi.org/10.1371/journal.pone.0078640.

29. Monnier A, Larsson H, Nero H, Djupsjöbacka M, Äng BO. A longitudinal observational study of backpain incidence, risk factors and occupational physical activity in Swedish marine trainees. BMJ Open 2019; 9(5): e025150. https://doi.org/10.1136/bmjopen-2018-025150.

Authors:

Irina M. Goncharenko - MD, PhD student, Saratov Hygiene Medical Research Center of Federal Scientific Center for Medical and Preventive Health Risk Management Technologies, Saratov, Russia. https://orcid.org/0000-0002-3734-3408.

Nataliya E. Komleva - MD, DSc, Head of the Saratov Hygiene Medical Research Center of Federal Scientific Center for Medical and Preventive Health Risk Management Technologies, Saratov, Russia. https://orcid.org/0000-0001-5360-712X.

Andrey A. Chekhonatsky - MD, DSc, Head of the Department of Neurosurgery n.a. E.I. Babichenko, Saratov State Medical University, Saratov, Russia. https://orcid.org/0000-0003-3327-1483. 